\title{
Comunicação
}

[Communication]

\section{Freqüência da displasia coxofemoral em cães da raça Pastor Alemão}

[Frequency of hip dysplasia in German Shepherd dogs]

\author{
G.S. Barros ${ }^{1}$, G.L.T. Vieira ${ }^{2}$, L.R. Vianna ${ }^{3}$, R.C.S. Tôrres ${ }^{4 *}$ \\ ${ }^{1}$ Aluno de graduação - EV-UFMG - Belo Horizonte, MG \\ ${ }^{2}$ Aluna de pós-graduação - EV-UFMG - Belo Horizonte, MG \\ ${ }^{3}$ Polícia Militar do Estado de Minas Gerais - Belo Horizonte, MG \\ ${ }^{4}$ Escola de Veterinária - UFMG - Belo Horizonte, MG
}

O termo displasia coxofemoral (DCF) significa desenvolvimento anormal da articulação coxofemoral, sendo a doença descrita no cão pela primeira vez em 1935 (Brass, 1989). A DCF pode acometer várias raças de cães, entretanto é mais comum nas de médio e grande portes (Cook et al., 1996; Ettinger e Feldman, 2004; Kealy e Macallister, 2005).

Há uma predisposição genética para a ocorrência da DCF, de forma que vários genes estão envolvidos (Tôrres et al., 2001). Os cães geneticamente predispostos à DCF nascem com articulações coxofemorais normais, e as anormalidades associadas à doença desenvolvem-se à medida que os filhotes crescem. Apesar de vários fatores estarem relacionados ao desenvolvimento da doença, a frouxidão articular é considerada fator primário para o estabelecimento da DCF (Cook et al., 1996; Lust, 1997; Ettinger e Feldman, 2004; Kealy e MacAllister, 2005).

Os animais doentes podem apresentar claudicação uni ou bilateral, dorso arqueado, peso corporal deslocado em direção aos membros anteriores, rotação lateral desses membros e andar bamboleante. Os sinais clínicos nem sempre são compatíveis com os achados radiológicos (Brass, 1989).

Os exames radiográficos caracterizam a DCF pelo arrasamento do acetábulo, achatamento da cabeça do fêmur, subluxação ou luxação

Recebido em 27 de agosto de 2008

Aceito em 1 de dezembro de 2008

*Autor para correspondência (corresponding author)

E-mail: rtorres@vet.ufmg.br

Apoio: FAPEMIG coxofemoral e alterações secundárias da articulação (Lust, 1997; Kealy e MacAllister, 2005).

Segundo McLaughlin Jr. e Tomlinson (1996), a DCF em geral ocorre bilateralmente, não sendo incomum que uma articulação esteja mais severamente afetada que a outra. Keller e Corley (1989) verificaram 23,6\% de DCF em cães da raça Pastor Alemão e $20,1 \%$ de comprometimento unilateral, enquanto Henricson et al. (1966) observaram que 11\% dos cães avaliados apresentavam DCF unilateral.

Morgan (1986) considerou a manifestação assimétrica da DCF sob dois aspectos diferentes: unilateral, quando uma articulação é normal e a outra afetada, e bilateral, quando ambas as articulações estão afetadas, porém com graus diferentes. Em seu estudo retrospectivo de 11 anos, encontrou $30,9 \%$ de assimetria em cães displásicos da raça Pastor Alemão, sendo 16,4\% unilateral e $14,5 \%$ bilateral. Tôrres et al. (1999) estudaram a freqüência e a assimetria da DCF em cães da raça Pastor Alemão no estado de Minas Gerais e encontraram 72,4\% dos animais displásicos. Entre estes, 5,3\% apresentaram displasia bilateral assimétrica e 5,3\%, unilateral.

Este trabalho teve como objetivo determinar a ocorrência da DCF em cães da raça Pastor Alemão pertencentes à Polícia Militar do Estado de Minas Gerais (PMMG) e quantificar a manifestação assimétrica da doença no grupo estudado. 
Foram analisadas 123 radiografias de cães da raça Pastor Alemão, 76 de machos e 47 de fêmeas, obtidas do arquivo do Hospital Veterinário da Escola de Veterinária da UFMG. Os exames radiográficos foram realizados entre abril de 2001 e julho de 2004. A idade média dos cães foi de 33,8 $\pm 23,5$ meses. Os animais eram assintomáticos e foram encaminhados exclusivamente para avaliação das articulações coxofemorais. Os exames deram-se por meio de tranqüilização prévia com cloridrato de xilazina $(1 \mathrm{mg} / \mathrm{kg}$ - IM) e incidência radiográfica na posição padrão utilizada para o diagnóstico da DCF, com os animais mantidos em decúbito dorsal, com os membros posteriores completamente estendidos, os fêmures paralelos entre si e em relação à coluna vertebral e a pélvis em simetria. Utilizaram-se filmes de tamanho 30 $\mathrm{x} 40 \mathrm{~cm}$. As radiografias foram avaliadas sobre negatoscópio com base na classificação proposta por Brass et al. (1978).

Observou-se freqüência de $89,4 \%$ de cães displásicos, ocorrendo a doença em 91,5\% das fêmeas e $88,2 \%$ dos machos. Apenas $0,8 \%$ dos cães apresentaram articulações coxofemorais normais e $9,8 \%$ foram classificados como suspeitos. A freqüência de DCF encontrada foi maior que a relatada em cães da mesma raça por Keller e Corley (1989), 23,6\%, e por Tôrres et al. (1999), 72,4\%, no Estado de Minas Gerais. A alta freqüência de DCF verificada pode ser explicada pela ausência de um programa de controle no período estudado. Por se tratar de um problema muitas vezes debilitante, infere-se que este pode estar causando grande impacto negativo no trabalho realizado pelos animais da PMMG.

Quanto à ocorrência de assimetria entre os animais displásicos, encontrou-se freqüência de $23,6 \%$, valor menor que o encontrado por Morgan (1986), 30,9\%, e mais elevado que o relatado por Tôrres et al. (1999), 10,6\%. Levando-se em conta o tipo de assimetria, 17,3\% dos cães displásicos apresentaram DCF bilateral assimétrica, acima do encontrado por Morgan (1986), 14,5\%, e Tôrres et al. (1999), 5,3\%, e $6,3 \%$ DCF unilateral, menor que o encontrado por Keller e Corley (1989), 20,1\%, Henricson et al. (1966), 11\%, e Morgan (1986), 16,4\%, e próximo ao encontrado por Tôrres et al. (1999), $5,3 \%$. Na Tab.1, há um resumo dos resultados encontrados.

Tabela 1. Freqüência e assimetria de displasia coxofemoral nos cães da raça Pastor Alemão da Polícia Militar do Estado de Minas Gerais

\begin{tabular}{|c|c|c|c|c|c|c|c|c|}
\hline \multirow{4}{*}{$\begin{array}{l}\text { Animais } \\
\text { (n) }\end{array}$} & \multicolumn{8}{|c|}{ Displasia } \\
\hline & \multirow{2}{*}{\multicolumn{2}{|c|}{ Total }} & \multicolumn{4}{|c|}{ Bilateral } & \multirow{2}{*}{\multicolumn{2}{|c|}{ Unilateral }} \\
\hline & & & \multicolumn{2}{|c|}{ Simétrica } & \multicolumn{2}{|c|}{ Assimétrica } & & \\
\hline & $\mathrm{n}$ & $\%$ & $\mathrm{n}$ & $\%$ & $\mathrm{n}$ & $\%$ & $\mathrm{n}$ & $\%$ \\
\hline Fêmea (47) & 43 & 91,5 & 33 & 76,7 & 7 & 16,3 & 3 & 7,0 \\
\hline Macho (76) & 67 & 88,2 & 51 & 76,1 & 12 & 17,9 & 4 & 6,0 \\
\hline Total (123) & 110 & 89,4 & 84 & 76,4 & 19 & 17,3 & 7 & 6,3 \\
\hline
\end{tabular}

Assim como Keller e Corley (1989), McLaughlin Jr. e Tomlinson (1996) e Tôrres et al. (1999), constatou-se que a DCF é uma alteração articular predominantemente bilateral e que há uma pequena porcentagem de manifestação assimétrica unilateral, que exige certa atenção para o correto estabelecimento do diagnóstico da doença. A freqüência da DCF em cães da raça Pastor Alemão na população estudada é alta e indica a necessidade de adoção de um programa de controle eficiente.

Palavras-chave: cão, displasia coxofemoral, assimetria

\section{ABSTRACT}

One hundred twenty-three radiographs of German Shepherd dogs (47 females and 76 males) from Military Police of Minas Gerais State were studied from April 2001 to july 2004, with the purpose of establishing the frequency and asymmetry of hip displasia. The radiographs were taken with the animals in the ventrodorsal position, with the limbs parallel and the pelvis symmetric. The average age of the dogs was 33.8 \pm 23.5 months-old. The study indicated that $89.4 \%$ of them had hip dysplasia $(91.5 \%$ of 
females and $88.2 \%$ of males), being $6.3 \%$ unilateral, $17.3 \%$ bilateral asymmetric, and $76.4 \%$ bilateral symmetric. The frequency of hip displasia in the studied population was high, indicating the necessity of an efficient control program of the disease.

Keywords: dog, hip dysplasia, asymmetry

\section{AGRADECIMENTOS}

À Escola de Veterinária da UFMG, em nome da equipe de pesquisadores, agradece à $\mathrm{PMMG}$ por ter autorizado a publicação deste trabalho.

\section{REFERÊNCIAS BIBLIOGRÁFICAS}

BRASS, W.; FREUDIGER, U., MULLER, L.F. et al. Bericht der huftgelenkdysplasieKommission. Kleintierpraxis, v.23, p.169-180, 1978.

BRASS, W. Hip dysplasia in dogs. J. Small Anim. Pract., v.30, p.166-170, 1989.

COOK, J.L.; TOMLINSON, J.L.; CONSTANTINESCU, G.M. Pathophysiology, diagnosis, and treatment of canine hip dysplasia. Comp. Cont. Educ. Pract. Vet., v.18, p.853-867, 1996.

ETTINGER, S.J.; FELDMAN, E.C. Tratado de medicina interna veterinária: doenças do cão e do gato. 5 ed. Rio de Janeiro: Guanabara Koogan, 2004. 2156p.

HENRICSON, B.; NORBERG, I.; OLSSON, S.E. On the etiology and pathogenesis of hip dysplasia: A comparative review. J. Small Anim. Pract., v.7, p.673-688, 1966.
KEALY, J.K.; MACALLISTER, H. Diagnostic radiology and ultrasonography of the dog and cat. St. Louis: Elsevier Saunders, 2005. 512p.

KELlER, G.G.; CORLEY, E.A. Canine hip dysplasia: investigating the sex predilection and the frequency of unilateral CHD. Vet. Med., v.84, p.1162-1166, 1989

LUST, G. An overview of the pathogenesis of canine hip dysplasia. J. Am. Vet. Med. Assoc., v.210, p.1443-1445, 1997.

McLAUGHLIN Jr., R.; TOMLINSON, J. Radiographic diagnosis of canine hip dysplasia. Vet. Med., v.91, p.36-47, 1996.

MORGAN, J.P. Canine hip dysplasia: asymmetry of change. Calif. Vet., v.40, p.17-20, 1986.

TÔRRES, R.C.S.; FERREIRA, P.M.; SILVA, D.C. Freqüência e assimetria da displasia coxofemoral em cães Pastor-Alemão. Arq. Bras. Med. Vet. Zootec., v.51, p.153-156, 1999.

TÔRRES, R.C.S.; ROCHA, B.D; SILVA, E.F. Freqüência da displasia coxofemoral em cães da raça Labrador Retriever no estado de Minas Gerais. Arq. Bras. Med. Vet. Zootec., v.5, p.445446, 2001. 